\title{
O SUJEITO-CIDADÃO COMO PROTAGONISTA DO DESENVOLVIMENTO SUSTENTÁVEL POR INTERMÉDIO DA EDUCAÇÃO: A CONTRIBUIÇÃO DE EDGAR MORIN
}

\author{
Elouise Mileni Stecanella ${ }^{1}$ \\ Giovanni Olsson ${ }^{2}$
}

\begin{abstract}
RESUMO: O presente estudo tem como objetivo compreender como a educação contribui para que o cidadão desenvolva práticas de desenvolvimento sustentável, sob um viés de Edgar Morin. Por meio de um estudo teórico, a pesquisa utilizou a técnica bibliográfica, com emprego de obras específicas sobre a temática, além do uso de documentos de organizações internacionais direcionados ao assunto. Foi possível aduzir que, por meio de ideais dispostos por Edgar Morin em "Os sete saberes necessários à educação do futuro", a educação é essencial para que o sujeito-cidadão promova ações para um desenvolvimento sustentável.
\end{abstract}

Palavras-chave: educação; desenvolvimento sustentável; Edgar Morin; sujeito-cidadão; protagonismo social.

\section{THE CITIZEN AS A PROTAGONIST OF SUSTAINABLE DEVELOPMENT THROUGH EDUCATION: EDGAR MORIN'S CONTRIBUTION}

\begin{abstract}
This study aims to verify how education has contributed to citizen's exercise of sustainable development, according to Edgar Morin. Through a theoretical study, the research used a bibliographic technique, with the realization of specific works on the subject, as well as the use of documents from international organizations directed to this topic. It is possible to verify that, through the ideas presented by Edgar Morin in "You have the necessary knowledge for the education of the future", education is essential for the subject to promote actions for sustainable development.
\end{abstract}

Keywords: education; sustainable development; Edgar Morin; subject-citizen; social protagonism.

\section{INTRODUÇÃO}

\footnotetext{
${ }^{1}$ Mestranda em Direito pela Universidade Comunitária da Região de Chapecó - UNOCHAPECÓ, com taxa de Mestrado PROSUC/CAPES. Membro do Grupo de Pesquisa Relações Internacionais, Direito e Poder (UNOCHAPECÓ). E-mail: elouise.stecanella@unochapeco.edu.br; Currículo Lattes: http://lattes.cnpq.br/4238863472745393.

${ }^{2}$ Doutor em Direito pela Universidade Federal de Santa Catarina. Professor do Programa de Pós-Graduação Mestrado em Direito da Universidade Comunitária da Região de Chapecó - UNOCHAPECÓ. E-mail: golsson71@gmail.com. Currículo Lattes: http://lattes.cnpq.br/1890264911560158
} 
O trabalho objetiva examinar como a educação contribui para que o cidadão desenvolva práticas de desenvolvimento sustentável atrelado à Agenda 2030 da Organização das Nações Unidas (ONU), sob um viés de Edgar Morin e o escrito "Os sete saberes necessários à educação do futuro". Especificamente, busca-se: explanar sobre o sujeitocidadão e o papel transformador do protagonismo social; contextualizar a vida e a obra de Edgar Morin, mais precisamente a sua proposta em "Os sete saberes necessários à educação do futuro"; e, por fim, contextualizar o desenvolvimento sustentável na Agenda 2030 da ONU e os mecanismos para sua concretização por meio da educação e do sujeito-cidadão.

O tema abrange a educação no âmbito do desenvolvimento sustentável, cuja análise é realizada com base em "Os sete saberes necessários à educação do futuro" de Edgar Morin. Para tanto, realizar uma análise do referido escrito, em um contexto de desenvolvimento sustentável disposto na Agenda 2030, é primordial para refletir sobre o sujeito-cidadão, e como a educação perpassa a sua atuação.

Por se tratar de um estudo teórico, a metodologia engloba uma pesquisa de caráter qualitativo e utiliza o método dedutivo. Recorrerá a estudos bibliográficos sobre a temática estudada, com o emprego de documentos de organizações internacionais direcionados ao assunto.

Diante disso, o trabalho foi dividido em três tópicos. O primeiro, voltado para o estudo do sujeito-cidadão. O segundo tópico direciona-se para o estudo da vida e obra de Edgar Morin, destacando-se o escrito "Os sete saberes necessários à educação do futuro". Por fim, no terceiro tópico, e no intuito de responder à problemática investigativa proposta, o artigo volta-se para a compreensão da relação desse marco teórico com o desenvolvimento sustentável na Agenda 2030 da Organização das Nações Unidas e os mecanismos para sua concretização por meio da educação e do sujeito-cidadão.

\section{O PROTAGONISMO DO SUJEITO-CIDADÃO}

Para se compreender o sujeito-cidadão, importante notar o conceito de cidadania e suas implicações. A disposição de uma concepção de cidadania decorre da constituição de um conceito de cidadania cosmopolita, que abrange ideais de cidadanias política, social, civil, econômica e intercultural (OLIVEIRA; QUEIROZ, 2016, p. 80). 
Um conceito de cidadania deve reunir um conjunto de direitos, no seu viés legal; uma reunião de responsabilidades, em uma compreensão moral; e também uma identificação pelos sujeitos à uma sociedade especificamente (CORTINA, 2005, p. 202). Diz a autora: "Poderíamos dizer, portanto, que o reconhecimento da cidadania social é conditio sine qua non na construção de uma cidadania cosmopolita que, por ser justa, faça com que todos os homens se sintam e se saibam cidadãos do mundo" (CORTINA, 2005, p. 210).

Cortina (2005, p. 202-210) propõe a universalização da cidadania social; a luta por uma globalização econômica que seja ética; e o estabelecimento de uma compreensão mínima de justiça, compartilhados por diferentes Estados, partindo do que as diferentes culturas têm em comum.

Por meio de um diálogo cooperativo para a concretização daquilo que é verdadeiro e justo, é possível identificar a verdade no interior de cada pessoa. Assim, para Cortina (2005, p. 195), “diálogo é, então, um caminho que compromete em sua totalidade as pessoas que estão envolvidas porque, neste contexto, deixam de ser meros expectadores para converteremse em protagonistas de uma tarefa compartilhada", ou, em outras palavras, "a busca compartilhada do verdadeiro e do justo, e a resolução justa dos conflitos que vão surgindo ao longo da vida".

Diante disso, compreende-se que o pertencimento a grupos, comunidades, movimentos e associações da sociedade civil proporciona uma adequada rota para a compreensão de bom cidadão. Além disso, é importante mencionar o interesse do próprio ser humano em pertencer a uma comunidade, ou seja, a uma sociedade civil, como movimentos sociais, igreja, entre outros. A pertença a grupos e movimentos é o melhor caminho para o aprendizado de um cidadão responsável (OLIVEIRA, 2003, p. 518).

Numa concepção da sociedade civil, verifica-se que é nesse meio que ocorrem lutas sociais com o intuito de liberdade, justiça social, cidadania e demais direitos, proporcionando um ambiente de proteção dos interesses comuns de cidadãos, atrelado a um espaço cultural e com relações econômicas e do Estado (OLIVEIRA, 2003, p. 519).

Além disso, percebe-se que o interesse dos indivíduos pelos temas globais é crescente, o que difere dos cidadãos do passado, convergindo para uma cidadania global. Assim, há necessidade de uma governança em nível mundial, uma vez que o Estado não se mantém mais como o núcleo central, mas como mais um de seus múltiplos atores como os conglomerados transnacionais (OLIVEIRA, 2003, p. 534-535). 
Diante disso, em um mundo que se transforma constantemente, a cidadania também se modifica, devendo acompanhar o ritmo transnacional, tentando construir uma cidadania mundial, convertendo-o no cidadão de uma só sociedade civil, com a absorção de fronteiras e nacionalidades (OLIVEIRA, 2003, p. 534-535).

Nesse contexto, são as práticas dos cidadãos que defendem o aspecto público da política através da sua ação, e as relações de poder são identificadas na sua experiência e ligadas à prática cidadã (BERGER; ORTEGA, 2010, p. 140-141). Tais valores explicitam que todo cidadão precisa ver-se como sujeito participante do contexto social, e, por participante, é aquele que atua ativamente e age ante a situações sociais apresentadas.

Não por acaso, a educação para o exercício do controle externo social pelo sujeitocidadão é a mais significativa para a sua atuação (MACEDO JUNIOR; MACEDO, 2010, p. 359). Como exemplo, cita-se o sistema de ensino suíço que desenvolve uma cidadania ativa dos sujeitos a ela pertencentes, sendo que também o Estado é garantidor de condições econômicas e sociais adequadas, com o intuito de impulsionar o exercício da cidadania. Percebe-se, assim, que a educação é essencial para a cidadania e a conservação da democracia, possuindo aceitação e defesa não apenas no meio político, através de governantes suíços, mas também por especialistas da área da educação e do controle externo (MACEDO JUNIOR; MACEDO, 2010, p. 363).

Paulo Freire (1979, p. 14) apresentava: "a educação é uma resposta da finitude da infinitude”. Nesse sentido, a educação do homem é possível, por ser um ser não terminado. Essa educação implica num alcance e "o homem deve ser o sujeito de sua própria educação. Não pode ser o objeto dela. Por isso, ninguém educa ninguém".

A investigação pela educação não pode ser individual, e deve ser realizada em conjunto com outras "consciências", porque "o homem não é uma ilha". A partir daquela hora em que o homem compreende sua o mundo em que vive, ele pode verificar circunstâncias desafiadoras e buscar soluções, e, assim, é capaz de modificar o meio em que vive (FREIRE, 1979, p. 14-16).

Portanto, a legitimação se deve, antes de tudo, pela percepção do lugar do sujeito no mundo e pela noção de que a qualidade de sujeito permite a ele agir no mundo, de forma a transformá-lo em local de autonomia e não de opressão.

As ações do dia a dia são passíveis de serem construídas pela participação e cooperação entre os diversos sujeitos, sendo que o seu desenvolvimento ocorre em um plano, 
que pode ser considerado o seu local e cotidiano. Através dessa compreensão é que há a participação de diversos atores, como empresários, empregados, terceiro setor, governantes, entre outros. Nesse sentido, o plano local é em sua maioria responsável pela busca de soluções para conflitos, uma vez que há a possibilidade de negociações e atuações de forma ágil (SACHS, 2003, p. 143).

Tem-se também a constatação decorrente do "processo evolutivo onde a educação assume um papel fundamental nas dinâmicas de mudança e que o nível do seu sucesso é em parte condicionado pela capacidade em envolver todos os agentes", o que se traduz "numa afirmação de cidadania, através de ações concretas que, no caso do ambiente, exigem uma escala global" (ALHO, 2019, p. 190-191).

Antes de se prosseguir, é necessário esclarecer que a palavra educação, aqui utilizada, não se reduz à educação formal, mas sim a todas as formas, processos ou meios que a sociedade utiliza para desenvolver a cidadania. Por isso, e nesse sentido mais amplo, é fundamental compreender como a proposta de Edgar Morin pode contribuir para sua afirmação em termos de futuro da humanidade.

\section{EDGAR MORIN E OS SABERES NECESSÁRIOS À EDUCAÇÃO DO FUTURO}

Para se compreender os ideais de Edgar Morin, importante demarcar a sua origem. $\mathrm{O}$ nascimento de Morin se deu em 8 de julho de 1921, na cidade de Paris, na França. As suas inquietações referentes à vida, futuro e pátria tiveram lugar a partir do preconceito que lhe era acometido na escola, em razão da sua origem judaica. $O$ falecimento da sua mãe em tenra idade é marcado como um importante motivador na sua vida, e moldou os seus destinos profissionais e acadêmicos (PETRAGLIA, 2011, p. 19).

Petraglia relata que, "com a perda da sua mãe aos nove anos de idade, as dúvidas e as tristezas aumentam e passa, então, a cultivar a saudade e a esperança", e a "esperança" aqui era de um novo futuro, ou "de uma energia cósmica, capaz de encaminhar sua vida e seus sonhos para alguma direção que só nos inspira um ideal” (PETRAGLIA, 2011, p. 19-20).

$\mathrm{Na}$ sua formação acadêmica, cursou Economia Política, e realizou estudos em História, Geografia e Direito, também frequentando disciplinas de vários outros campos do 
conhecimento, sempre ampliando seus horizontes, e identificando-se simultaneamente como antropólogo, sociólogo e filósofo (PETRAGLIA, 2011, p. 21).

Sua contribuição abarca diversas áreas, com destaque para a epistemologia, a cultura e a educação, principalmente por meio do pensamento da complexidade. Na sua produção acadêmica, busca superar estruturas deterministas e fragmentadas do saber a partir da sua larga formação, transitando suas obras e escritos por vários segmentos (MORIN, 2010, p. 68).

“O ano zero da Alemanha” foi sua primeira obra, com publicação no ano de 1946, em que retrata as verdades vividas e observadas durante o período de guerra na Alemanha (PETRAGLIA, 2011, p. 21), já impregnado dessa visão de mundo mais alargada, o que foi seguido por uma vasta e diversificada bibliografia. No Brasil, foram publicados: "O Enigma do Homem” (1973), “O método" (1977, 1980 1986, 1984, 2001 e 2004), "Introdução ao pensamento complexo" (1990), "Saberes globais e saberes locais: o olhar transdisciplinar" (2000), "Ciência com consciência" (2002), “A religação dos saberes" (2001) e - o que nos interessa sobremaneira aqui - o escrito "Os setes saberes necessários à educação do futuro" (1999).

Este último, que merece atenção neste trabalho, foi publicado em 1999, e decorreu de um projeto muito importante para toda a humanidade. Ele surgiu do convite de Gustavo López Ospina, Diretor do projeto transdisciplinar "Educação para um Futuro Sustentável” da UNESCO, que o chamou para compartilhar suas ideias e concepções sobre a educação do futuro, diante da sua visão transdisciplinar para uma educação integral do ser humano, sem fragmentação do conhecimento ou de seus saberes (MORIN, 2000, p. 11-12).

Morin, nesse escrito, não se debruça sobre uma esfera da educação específica. A educação, como ali tratada, é um fenômeno social e político amplo, que não se restringe a uma instituição de ensino ou, então, a uma sala de aula, e carece de apresentar superações ao conhecimento dividido em compartimentos que dispõe os educandos como meras pessoas que recebem informações desconexas, sem que a educação realmente ocorra (FARIAS; SANTOS, 2015, p. 266).

Nesse sentido, e numa de suas célebres preleções, o conhecimento fragmentado e desconexo em disciplinas e matérias são, em sua maioria, ineficientes para realizar a relação entre as partes e o todo, motivo pelo qual, "deve ceder lugar a um modo de conhecimento capaz de conceber os objetos em seus contextos, em seus complexos, em seus conjuntos" (MORIN, 2015, p. 100). 
Coaduna com o disposto uma palestra proferida por Ken Robinson no portal de conferências TED Talks (2006, n.p.), intitulada "Será que as escolas matam a criatividade?".

Robinson (2006, n.p.) aponta que o atual sistema educacional suprime a criatividade e a curiosidade inatas dos jovens ao forçá-los a se configurarem dentro de um modelo escolar unidimensional. Esse molde pode funcionar bem para alguns. Porém, para a maioria, os desejos e competências naturais são, na melhor das suposições, afastados. Na pior, são prontamente destruídos pelo sistema educacional moderno.

Diante disso, conclui Robinson (2006, n.p.) que uma perspectiva para o futuro seria a aplicação de um novo modelo de ecologia humana, um que prime pela reconstituição do poder da capacidade humana, que compreenda que o desenvolvimento humano não é uma ação linear e mecânica, porém orgânica. Uma educação ideal deve preconizar que as pessoas busquem suas próprias respostas e se preparem para atender às diferentes circunstâncias.

Morin (2000, p. 13-18) parte do caráter multidimensional do fenômeno do conhecimento; da compreensão da obscuridade escondida no coração de uma noção destinada ao esclarecimento de todas as coisas; da ameaça vinda do conhecimento e que nos leva a buscar uma relação civilizada entre nós e o nosso conhecimento; e de uma crise característica do conhecimento contemporâneo, sem dúvida inseparável da crise do nosso século.

Para ele, os sete saberes para o futuro apresentados na obra abarcam: as cegueiras do conhecimento: o erro e a ilusão; os princípios do conhecimento pertinente; o ensinar da condição humana; o ensinar a identidade terrena; o enfrentamento das incertezas; o ensinar da compreensão; e a ética do gênero humano (MORIN, 2000, p. 13-18).

Na concepção de Edgar Morin, o modo de pensamento ou de conhecimento que se divide em fragmentações, compartimentaliza-se, dispõe-se por meio de disciplinas, encaminha-se para inteligência que é compreendida como cega, que não possibilita a articulação de um saber com outros saberes, não sendo o global aqui vislumbrado. Diante disso, há a perda de uma capacidade de promover uma globalização de conhecimentos e uma introdução de modo organizado, o que seria essencial para a compreensão plena do mundo da vida e do sujeito-cidadão (MORIN, 2015, p. 106-107).

Coaduna com o disposto o apontado no relatório para Organização das Nações Unidas para a Educação, a Ciência e a Cultura - UNESCO, da Comissão Internacional sobre Educação para o século XXI, em que a educação deve organizar-se em quatro pilares fundamentais do conhecimento, que são o aprender a conhecer, que sinteticamente significa 
obter ferramentas para a compreensão; aprender a fazer, a fim de possibilitar atitudes acerca do meio em que vive o indivíduo; aprender a viver juntos, estabelecido com o intuito de colaborar com os demais indivíduos em suas ações; e por fim o aprender a ser, que em resumo abrange os pilares já expostos (UNESCO, 2003, p. 89-101). Esses pilares fundamentais encontram-se interligados, e que atuantes conjuntamente são capazes de auxiliar na formação integral do aprendiz, segundo o que apontam Rafael Henriques Nogueira Diniz et al (2014, p. $6)$.

Os quatro pilares do conhecimento devem ser sempre observados e praticados, com o intuito de que a educação seja compreendida por todos como uma experiência global, difundida no decorrer da vida, seja no plano cognitivo, seja no plano prático, tanto para o indivíduo enquanto indivíduo, tanto para o indivíduo enquanto membro da coletividade (UNESCO, 2003, p 89-101). Requer-se, assim, que, através desses pilares,

[...] se ultrapasse a visão puramente instrumental da educação, considerada como a via obrigatória para obter certos resultados (saber-fazer, aquisição de capacidades diversas, fins de ordem econômica), e se passe a considerá-la em toda a sua plenitude: realização da pessoa que, na sua totalidade, aprende a ser. (UNESCO, 2003, p. 90).

A partir disso, tem-se que a educação deve abarcar um conhecimento que seja do mundo, ou seja, que se apresente em um complexo planetário, com a concepção de que o global deve ser abrangido, com ideias articuladas e conhecimentos organizados (MORIN, 2000, p. 64).

Atenta ele que, logo, "é preciso mudar profundamente o pensamento e o ensino" e "sua reforma contribuirá para elevar a consciência sobre os perigos e a comunidade de destino, uma vez que potencializará a ação transformadora a partir da base", e, ainda, "as iniciativas dispersas e a criatividade que nos pontos mais distantes do planeta colaboram hoje com as vias regeneradoras, receberão os impulsos necessários para que deixem de ser marginais"; ele adverte, por fim, que, "longe de ser um esforço iluminista, a reforma educativa há de se fundir com a reforma do pensamento, da política e do político”, o que consiste em uma autêntica reinvenção (MORIN; DÍAZ, 2016, p. 14).

Wickert (2006, p. 262) aponta que as estratégias de educação, com base na definição de suas habilidades, devem ser traçadas cognitivamente, o que auxilia na organização; metacognitivamente, que possibilita a tomada de consciência acerca da estratégia cognitiva; e 
matemagênicas, permitindo a reflexão e geração do aprendizado com o auxílio de mapas, modelos analógicos, resumos, entre outros, e o estímulo à realização de práticas de ensino mais complexas, como críticas às teorias e elaboração de novos conhecimentos. Prima-se, assim, pela busca constante do aprimoramento dos processos mentais, como argumentação, comparação, interpretação, e principalmente, pelo desenvolvimento de estratégias para a compreensão do meio.

Morin relata as incertezas, aduzindo que um ato decisório necessita cogitar sobre elas, com "a elaboração de uma estratégia que leve em conta as complexidades inerentes às próprias finalidades, que possa se modificar durante a ação em função dos imprevistos, informações, mudanças de contexto (...)" (MORIN, 2000, p. 91). Na concepção de sujeitocidadão, ele deve ser participante ativo da sociedade, com a preparação para as consequências de uma determinada ação, já que as incertezas sempre serão constantes, o que, inclusive, proporciona o conhecimento.

Para Morin e Díaz (2016, p. 3), o vínculo entre educação, cidadania e política transcende os laços que entretecem os interesses que se situam na educação e política como práticas centrais da atual sociedade, uma vez que concerne a universalidade do político e do educativo a condução sobre o destino da humanidade. Mais do que isso, e por meio da educação, busca-se alcançar um mundo de algumas certezas, porque ela contribui para uma formação crítica dos indivíduos no que se refere às concepções de mundo. Promove uma atuação cidadã diante da transdisciplinariedade que ultrapassa as especificidades de algo determinado, em prol de um afastamento das incertezas (REGERT et al, 2018, p. 34).

Democracia e educação caminham lado a lado, e esta é essencial para a construção de uma sociedade livre. E mais, necessita-se inserir e estimular práticas democráticas, perpetradas sobre valores culturais resilientes, ou seja, resistentes a crises e interferências, que devem ser expressivos o suficiente para lidar com a questão da sustentabilidade ao mesmo tempo em que sejam simples e apreensíveis (QUEIROZ, 2017, p. 254).

É importante destacar que o pluralismo deve estar presente em todas as práticas, uma vez que o desenvolvimento sustentável não se refere mais a um desenvolvimento linear, e sim ao reconhecimento da articulação de diferentes formas de organização e demandas, como sustentáculo de uma verdadeira sustentabilidade, pluridimenionsal e integrada. Para abrir caminhos à metamorfose da humanidade é preciso reinventar a educação, avançando pela via 
eu enlaça a cidadania com a transformação política e com as reformas do pensamento e ensino (MORIN; DÍAZ, 2016, p. 7).

Com essa breve explanação sobre Edgar Morin e o escrito basilar para o trabalho, o passo seguinte, então, é saber qual relação pode ser estabelecida dessa concepção de educação a atuação do sujeito-cidadão na perspectiva dos Objetivos de Desenvolvimento Sustentável da Agenda 2030 da ONU, como autêntico projeto civilizatório.

\section{A EDUCAÇÃo NA AGENDA 2030 SOB O VIÉS DA ATUAÇÃo DO SUJEITO- CIDADÃO}

No ano de 2010 foi realizada a Cúpula das Nações Unidas sobre os Objetivos do Milênio, sendo o seu intuito a discussão de meios para a aceleração da concretização dos referidos Objetivos, assim como a discussão de uma nova agenda de desenvolvimento posteriormente ao ano de 2015. Com isso, foi implementado um amplo e inclusivo sistema de consulta para questões de interesse global, voltado à construção dos Objetivos de Desenvolvimento Sustentável, que foi construído por muitos participantes e colaboradores (ONU, 2015, p. 1-2).

Para tanto, houve a criação de um Grupo de Trabalho Aberto sobre Objetivos de Desenvolvimento Sustentável (GTA-ODS), que representou, dentre os instrumentos da Organização das Nações Unidas, o auge da incorporação da abordagem pluridimensional do desenvolvimento sustentável (ONU, 2015, p. 1-41). Ressalta-se que a sua construção se deu sob o legado da agenda dos Objetivos de Desenvolvimento do Milênio, do ano de 2000.

O Grupo de Trabalho Aberto teve como encargo a efetivação de propostas para os Objetivos de Desenvolvimento Sustentável, sendo ele composto por 70 países, e também com sociedade civil, meio acadêmico e científico, e também as Nações Unidas. A finalização do trabalho ocorreu em 2014, com a conclusão de uma proposta, a qual foi submetida para a Assembleia Geral da ONU no ano de 2015, em Nova York, nos Estados Unidos, o que veio, posteriormente, a gerar a Agenda 2030 (ONU, 2015, p. 1-41), uma vez que esta proposta englobou a indicação dos 17 objetivos e das 169 metas que hoje são partes da Agenda 2030 (ONU, 2015, p. 1-2). 
A partir disso, como acima referido, em 2015, 193 países membros da ONU se reuniram em Nova York, nos Estados Unidos, adotando o documento "Transformando o nosso mundo: a Agenda 2030 para o desenvolvimento sustentável", havendo um comprometimento em tomar medidas ousadas e transformadoras nos próximos 15 anos, ou seja, até 2030 (ONU, 2015, p. 1-2). Compreende-se que a Agenda 2030 configura-se como um novo projeto civilizatório, para as pessoas, o planeta e a prosperidade, possuindo o lema de "não deixar ninguém para trás". Como já disposto, o projeto de governança para o período 2015-2030 propõe 17 Objetivos de Desenvolvimento Sustentável (ODS) e 169 metas, sendo este um ambicioso plano de ação para governos, sociedade civil, pessoas jurídicas, universidades, com Objetivos e metas que devem ser vistos de maneira integrada e indivisível (ONU, 2015, p. 1-2).

Pretende-se gerar um equilíbrio pelos países adotantes na pluridimensionalidade do desenvolvimento sustentável, fortalecimento da paz universal, concretizações de parceiras globais, melhorias de qualidade de vida, efetivação de novas formas de atuação pelos interessados, entre outros (ONU, 2015, p. 1-2).

Os objetivos e metas do desenvolvimento sustentável não são uma solução para os problemas existentes nas três dimensões da sustentabilidade. Pelo contrário, sugere uma mudança no comportamento da humanidade, em nível global. Conforme Barter e Russel (2012, p. 6), o desenvolvimento sustentável não indica apenas medidas para salvar o meio ambiente, mas ele trata da sobrevivência humana e do próprio planeta.

Diversas organizações como a Organização das Nações Unidas (ONU), Banco Mundial (BM), Organização Mundial do Comércio (OMC), blocos econômicos diversos, organizações não governamentais, movimentos sociais, religiosos, culturais, associações diversas, buscam promover e desenvolver projetos de desenvolvimento sustentável para um bem-estar global, todavia, suas consequências práticas se tornam limitadas em uma determinada localidade (MELO NETO; RIBEIRO, 2006, p. 168).

Nessa perspectiva, Amartya Sen (2000, p. 9) dispõe sobre uma nova tipologia de desenvolvimento sob o viés da sustentabilidade e da vida das pessoas porque "o desenvolvimento deve ser estendido não como expansão econômica exclusivamente", mas também na perspectiva de "expansão da educação, da liberdade política, do acesso à saúde, das condições de saneamento, da segurança para a juventude - com esperança -, para os adultos - com emprego -, e para os idosos - com aposentadoria". 
Assim, percebe-se que os efeitos práticos de ações sustentáveis se tornam mais plausíveis quando desenvolvidos pelos cidadãos. Para tanto, a educação pressupõe a garantia de acesso à informação, construção de eticidade, bem como a lapidação de concepção moral, espiritual, permitindo que haja uma visão mais acertada sobre os problemas da condição humana e conflitos do cotidiano (MELO NETO; RIBEIRO, 2006, p. 184). Nesse viés, Morin, em seu escrito "Os setes saberes necessários à educação do futuro", aponta para uma educação pautada em práticas pluralistas, com um enfoque transdisciplinar e coberta por incertezas, que auxiliam para um alastramento do conhecimento. A educação permite aproximar os indivíduos e oportuniza a propagação de diversas culturas, dando contextualizadas significações aos processos de ensino e aprendizagem.

Prova disso são as experiências e propostas desenvolvidas por jovens, professores, grupos de pesquisa e em geral por profissionais da educação que, com uma abordagem produtivista da educação, tem desenvolvido um pensamento crítico, propondo-se políticas educacionais que colaborem para a comunidade em que os envolvidos estão inseridos. Aguarda-se, na própria prática educativa, o fortalecimento das capacidades deliberativas e o desenvolvimento de sujeitos conscientes de que seu presente é afetado pela história, que inclua a memória de grandes populações derrotadas para gerar novas sensibilidades, novas solidariedades (FERNÁNDEZ-ALATORRE, 2018, p. 20).

Nessa concepção, pode-se citar como exemplo o caso de "Las Madres de Barrio Ituzaingó Anexo", em que as mulheres reclamam uma atenção efetiva sobre a saúde da população, diante da grande quantidade de pessoas doentes no bairro Ituzaingó Anexo, em Córdoba, na Argentina, pela utilização de agrotóxicos nas plantações de soja em áreas lindeiras (BERGER; ORTEGA, 2010, p. 139-140).

No caso de "Las Madres de Barrio Ituzaingó Anexo", a educação como um meio de concretização de Objetivo de Desenvolvimento Sustentável vem à tona, uma vez que as mães começaram a estudar e se informar sobre as relações entre contaminações por agrotóxicos e enfermidades, o que gerou um mapa de epidemiologia popular por elas idealizado. As suas ações fizeram com que fossem implantados, dentre outros, novos parâmetros ambientais para o local em que moravam, com reflexo no seu ordenamento jurídico, passando a admitir normas que alargaram o nível de distanciamento para uso de pesticidas em áreas periurbanas (BERGER et al, 2019, p. 98-99). 
A educação, portanto, é percebida como um fenômeno com profundas implicações multidimensionais que repercutem no desenvolvimento de todas as facetas do mundo da vida do ser humano, sendo o sujeito-cidadão precursor dessa concepção. Por meio da sua capacidade de agir, pensar, e exercer um posicionamento no mundo como agente transformador, ele proporciona condições para a concretização dos Objetivos de Desenvolvimento Sustentável.

Portanto, conclui-se que a abordagem transdisciplinar na educação representa um novo horizonte com muitas aplicações teórico-práticas, inclusive quando engloba a atuação do sujeito-cidadão, como econômicas, científicas, tecnológicas, artísticas, entre outros, conforme disposto na Agenda 2030 da ONU, e, nesse ponto, a compreensão holística e visionária de Edgar Morin pode ser considerada a sua maior inspiração.

\section{CONSIDERAÇÕES FINAIS}

O trabalho se referiu à contribuição da educação para que o cidadão desenvolva práticas de desenvolvimento sustentável atrelado à Agenda 2030 da Organização das Nações Unidas (ONU), na visão de Edgar Morin no escrito "Os sete saberes necessários à educação do futuro".

Como exposto, Morin aponta para uma educação pautada em práticas pluralistas, com um enfoque transdisciplinar, e coberta por incertezas, que auxiliam para um alastramento do conhecimento. Ela aproxima os indivíduos e oportuniza a propagação de diversas culturas, dando contextualizadas significações aos processos de ensino e aprendizagem. Assim, deve haver uma consciência reflexiva de si e do mundo, como uma nova ética da solidariedade, que implica mudança de atitude e perspectiva diante da vida

Diante disso, verifica-se que educação é aliada às ações constantes na Agenda 2030 da ONU, unindo o desenvolvimento e a sustentabilidade pluridimensional. Ela recomenda uma alteração nas ações dos indivíduos em nível global, assim como influi nas políticas promovidas pelos Estados. Proporciona uma efetivação dos 17 Objetivos de Desenvolvimento Sustentável (ODS) e 169 metas, integrados e indivisíveis, equilibrando as dimensões do desenvolvimento sustentável pelos países adotantes. 
O sujeito-cidadão é necessário para a efetivação do desenvolvimento e da sustentabilidade pluridimensional, tanto para uma concretização do pensamento de Morin, quanto para as disposições da Agenda 2030 da ONU, porque, por meio da sua capacidade de agir, pensar, e exercer um posicionamento no mundo como agente transformador, pela educação, permite promover ações necessárias para a efetivação dos Objetivos e Metas da referida Agenda. Com isso, observa-se um equilíbrio entre a questão econômica, a preservação do meio ambiente e o desenvolvimento social e institucional, o que é almejado na Agenda 2030 da ONU.

Portanto, a concepção de educação apontada por Edgar Morin é essencial para a Agenda 2030, por meio da atuação do sujeito-cidadão para a concretização dos Objetivos de Desenvolvimento Sustentável.

\section{REFERÊNCIAS}

ALHO, José Manuel. Educação e cidadania pela floresta Autóctone. Territorium: Revista Internacional de Riscos, Portugal, 26 (II), 2019. Disponível em: https://impactumjournals.uc.pt/territorium/article/view/1647-7723_26-2_14/5185. Acesso em: 12 mar. 2021.

BARTER, Nick; RUSSELL, Sally. Sustainable Development: 1987 to 2012 - Don't Be Naive, it's not about the Environment. In: 11TH AUSTRALASIAN CONFERENCE ON SOCIAL AND ENVIRONMENTAL ACCOUNTING RESEARCH (A-CSEAR). Proceedings... University of Wollongong, 2012. p. 1-18.

BERGER, Maurício; ORTEGA, Francisco. Poblaciones expuestas a agrotóxicos: autoorganización ciudadana en la defensa de la vida y la salud, Ciudad de Córdoba, Argentina. Physis: Revista de Saúde Coletiva, Rio de Janeiro, v. 20, n. 1, p. 119-143, 2010. Disponível em: https://www.scielo.br/scielo.php?pid=S0103-

73312010000100008\&script=sci_abstract\&tlng=es. Acesso em: 15 ago. 2020.

BERGER, Maurício Sebastián; PEREIRA, Reginaldo; SINEIRO, Cecília Carrizo; BIEGER, Andrey Luciano. Justiça ambiental e proteção de riscos dos agrotóxicos no Brasil: problematizações a partir do caso Las Madres de Barrio Ituzaingó Anexo, Córdoba, Argentina. Revista de Direito Econômico e Socioambiental, Curitiba, v. 10, n. 3, p. 92-126, set./dez. 2019.

CORTINA, Adela. Cidadãos do mundo: para uma teoria da cidadania. São Paulo: Edições Loyola, 2005.

FARIAS, Ana Paula Perardt; SANTOS, Renata Nazaré Machado Tárrio dos. Interdisciplinariedade no ensino superior: uma abordagem a partir da proposta de Edgar 
Morin. Saberes: Filosofia e Educação, v. 1, n. 12, p. 266, 2015. Disponível em: https://periodicos.ufrn.br/saberes/article/view/7064. Acesso em: 12 maio 2020.

FERNANDEZ-ALATORRE, Ana Corina. Para pensar la educación política en la educación formal. Educare, Heredia , v. 22, n. 2, p. 302-323, ago. 2018. Disponível em: http://www.scielo.sa.cr/scielo.php?script=sci_arttext\&pid=S140942582018000200302\&lng=en\&nrm=iso. Acesso em: 12 mar. 2021.

. Los jóvenes y las nuevas formas de acción colectiva. El caso de la Acampada Sur en el centro de Coyoacán. Revista Mexicana de Opinión Pública, Volume 18, January-June 2015. Disponível em:

https://www.sciencedirect.com/science/article/pii/S187073001571361X. Acesso em: 12 mar. 2021.

FREIRE, Paulo. Educação e mudança. 12a ed. Paz e Terra. Rio de Janeiro, 1979.

MACEDO JÚNIOR, Geraldo de Oliveira; MACEDO, Adriana Maria Bento. Controle Externo Social, Educação e Cidadania. Revista Controle - Doutrina e Artigos, v. 8, n. 1, p. 357-370, 30 jun. 2010. Disponível em: https://revistacontrole.tce.ce.gov.br/index.php/RCDA/article/view/93. Acesso em: 12 mar. 2021.

MELO NETO, Francisco Paulo de; RIBEIRO, Márcia Maria Gurgel. Desenvolvimento humano sustentável e educação: desafios para um novo tempo. Revista Educação em Questão, Natal, v. 27, n. 13, p. 164-191, set./dez. 2006. Disponível em:

https://periodicos.ufrn.br/educacaoemquestao/article/view/4496/3680. Acesso em: 12 mar. 2021.

MORIN, Edgar. Os sete saberes necessários à educação do futuro. 2. ed. Brasília: UNESCO/Cortez Editora, 2000.

Saberes globais e saberes locais: o olhar transdisciplinar. Rio de Janeiro: Garamond, 2010.

Ensinar a viver: manifesto para mudar a educação. Porto Alegre: Sulina, 2015.

Ciência com consciência. Trad. Maria D. Alexandre e Maria Alice Sampaio Dória. 5. ed. Rio de Janeiro: Bertrand Brasil, 2002.

A religação dos saberes. Tradução de Maria Amália de Oliveira. Rio de Janeiro: Bertrand, 2001.

MORIN, Edgar; DÍAZ, Carlos Jesús Delgado. Reinventar a educação: abrir caminhos para a metamorfose da humanidade. Tradução de Irene Reis dos Santos. São Paulo: Palas Athena, 2016.

OLIVEIRA, Roberto Dalmo Varallo Lima de; QUEIROZ, Glória Regina Pessôa Campello. O cotidiano, o contextualizado e a Educação em Direitos Humanos: a escolha de um caminho 
para uma Educação cidadã cosmopolita. Revista Iberoamericana de Educación, vol. 71, núm. 1, maio 2016. Disponível em: https://rieoei.org/historico/deloslectores/7446.pdf. Acesso em: 12 mar. 2021.

OLIVEIRA, Odete Maria de. A era da globalização e a emergente cidadania mundial. In: OLIVEIRA, Odete Maria de; JÚNIOR, Arno Dal Ri (Org.). Cidadania e Nacionalidade: efeitos e perspectivas nacionais - regionais - globais. Ijuí: Ed. UNIJUÍ, 2003.

\section{ORGANIZAÇÃO DAS NAÇÕES UNIDAS. Cúpula das Nações Unidas sobre o}

Desenvolvimento Sustentável: Transformar nosso mundo para as pessoas e o planeta. 2015. Disponível em: https://nacoesunidas.org/pos2015/cupula/. Acesso em: 24 ago. 2020.

Transformando nosso mundo: A Agenda 2030 para o desenvolvimento sustentável. 2015. Disponível em: https://nacoesunidas.org/wp-content/uploads/2015/10/agenda2030-ptbr.pdf. Acesso em: 25 ago. 2020.

ORGANIZAÇÃO DAS NAÇÕES UNIDAS PARA A EDUCAÇÃO, A CIÊNCIA E A CULTURA. Educação: um tesouro a descobrir. Disponível em: https://unesdoc.unesco.org/ark:/48223/pf0000109590_por. Acesso em: 20 fev. 2021.

PETRAGLIA, Izabel. Edgar Morin: a educação e a complexidade do ser e do saber. Petrópolis: Vozes, 2011.

QUEIROZ, Isaac Newton Lucena Fernandes de et al. Educação e Etnociência: caminhos da agenda 2030 para o desenvolvimento sustentável. Revista Ibero-Americana de Ciências Ambientais, v. 8, n. 2, p. 254, 2017. Disponível em:

https://sustenere.co/index.php/rica/article/view/SPC2179-6858.2017.002.0020/846. Acesso em: 02 jun. 2020.

DINIZ, Rafael Henriques Nogueira et al. A utilização da Robótica Educacional LEGO® nas aulas de Física do $2^{\circ}$ ano do Ensino Médio e os seus reflexos sobre o cotidiano dos alunos. Latin American Journal of Science Education,v. 1, n. 2, 2014. Disponível em: http://www.lajse.org/nov14/22009_Diniz.pdf. Acesso em: 10 abr. 2017

REGERT, Rodrigo; BAADE, Joel Haroldo; PEGORARO, Ludimar. As Pessoas, a Educação e o Futuro: reflexões num mundo de incertezas. Revista Interdisciplinar em Cultura e Sociedade, v. 4, n. 1, p. 34, 2018. Disponível em:

http://www.periodicoseletronicos.ufma.br/index.php/ricultsociedade/article/view/9311. Acesso em: 22 maio 2020.

SACHS, Ignacy. Inclusão social pelo trabalho. Rio de Janeiro: Editora Garamont, 2003.

SEN, Amartya. Desenvolvimento como liberdade. São Paulo: Companhia das Letras, 2000.

WICKERT, Luciana Fim. Desemprego e juventude: jovens em busca do primeiro emprego.

Revista Psicologia: ciência e profissão, Brasília, v. 26, n. 2, jun. 2006, p. 258-269.

Disponível em: http://www.scielo.br/scielo.php?script=sci_arttext\&pid=S1414silva98932006000200008\&lng=en\&nrm=iso. Acesso em: 28 fev. 2021. 